\title{
Pressure Gradient Control Strategies Based on Disturbance Rejection for Typical Pharmaceutical Cleanrooms
}

\author{
Chunwang Li ${ }^{1}$, Xiaojun Ma1 ${ }^{1}$ Chun-E Huang2* \\ ${ }^{1}$ College of Biochemical Engineering, Beijing Union University, Beijing, China \\ ${ }^{2}$ Institute of Fundamental and Interdisciplinary Sciences, Beijing Union University, Beijing, China \\ Email: ‘hce_137@163.com
}

How to cite this paper: Li, C.W., Ma, X.J. and Huang, C.-E. (2021) Pressure Gradient Control Strategies Based on Disturbance Rejection for Typical Pharmaceutical Cleanrooms. World Journal of Engineering and Technology, 9, 555-564.

https://doi.org/10.4236/wjet.2021.93038

Received: June 22, 2021

Accepted: August 3, 2021

Published: August 6, 2021

Copyright $\odot 2021$ by author(s) and Scientific Research Publishing Inc. This work is licensed under the Creative Commons Attribution International License (CC BY 4.0).

http://creativecommons.org/licenses/by/4.0/

\section{(c) (i) Open Access}

\begin{abstract}
Keeping pressure gradient is an excellent approach to prevent the reveal of airflow direction and cross infection in manufacturing circumstances of pharmaceutical cleanrooms, thus how to keep cleanroom's pressure is critical. In the paper, we study a positive pressure pharmaceutical cleanroom system which is composed by a cleanroom and an airlock. We divide the system's disturbances into step disturbance, ramp disturbance and sine wave disturbance. We design its pressure gradient control strategies, including CAV control, PID control and active-disturbance-rejection-control. We build the system's model and make simulations based on Matlab/Simulink software platform. Results show that active-disturbance-rejection-control algorithm has good capabilities for shorter responding time and lower overshot of the pressure gradient. The results reveal that active-disturbance-rejection-control method has good control performances in responding time, accuracy and disturbance rejection.
\end{abstract}

\section{Keywords}

Pressure Gradient, Pharmaceutical Cleanrooms, Airlock, Active-Disturbance-Rejection-Control, PI Control

\section{Introduction}

With the fast development of precision manufacturing and cleaner production, the number and scale of cleanrooms increase rapidly over the world. In the United States, cleanrooms space grew from 4.2 million $\mathrm{m}^{2}$ in 1993 to 15.5 million $\mathrm{m}^{2}$ in

${ }^{*}$ Corresponding author. 
2015 [1], average growth rate was about $11.7 \%$ per year. In China, growth rate of cleanrooms is about $26.4 \%$ per year. Most of the cleanroom space is pharmaceutical cleanrooms, the problem how to keep pressure gradient among cleanrooms is critical. Adaptive pressure gradient between adjacent cleanrooms can keep good manufacturing circumstances in preventing the reveal of airflow direction and cross infection [2] [3] [4] [5].

In present, there are two typical controller methods. One approach is constant air volume (CAV), the cleanroom's pressure difference (PD) is maintained by tuning manually supply or return airflow valves, then the valves are fixed when the system is working. However, after the system runs a long time, the change of the setting or restarting the system, workers must tune again valves and change the supply or return airflows [3] [6] [7]. Another approach is variable air volume (VAV), supply airflow is fixed for keeping air change rate of the cleanroom and designed cleanroom level. The pressure difference is maintained around the designed value based on tuning return airflow in real time by PID controllers [4] [7].

However, there exist many problems in the control of the pressure difference in cleanrooms. One problem is there are many disturbances in cleanroom system, such as open and close of the door, the periodic change between occupied time and unoccupied time, and so on. These disturbances can cause the pressure difference frequent vibration, long responding time and big overshot [8]. Another problem is that almost all cleanrooms have the high design pressure difference for maintaining manufacturing circumstance, this causes huge energy waste [9]. Thus, a good method with strong disturbance rejection and high precision in controlling pressure difference in cleanroom can attract researcher's attention.

Active-disturbance-rejection-control (ADRC) algorithm was proposed in [10], its main idea is to estimate actively the whole disturbances of the system which caused by the unknown dynamics and external disturbances, compensate the disturbance using control laws, and obtain strong disturbance rejection ability [11] [12]. In 2003, Professor Gao in Cleveland State University proposed linear-active-disturbance-rejection-control (LADRC) [13], the research has attempted to simplify the controller structure and the tuning parameters of the ADRC, promote the technology rapidly development in its applications and theory. The algorithm was applied in thermal power generation [14] [15] [16] [17], air-condition system [18], aerospace [19], magnetic suspension [20], heat emission [21] etc.; The technology is also applied in producing the Parker Parflex hose extrusion facility [22] and controller chips in Texas Instruments that run LineStream's SpinTAC software [23] [24].

In the paper, we divide the disturbances into step disturbance (caused PD to increase and decrease suddenly), ramp disturbance (change of PD slowly) and periodic disturbance (change of operating model, fan vibration). We build cleanroom model composed by a cleanroom and an airlock on Matlab/Simulink software platform, design CAV control, PID control and active-disturbance-rejection-control to keep the cleanroom's PD. Results show that active-disturbance-rejection-control 
has advantages in responding time and disturbance rejection, and good capabilities in rejecting disturbance and control precision.

\section{Cleanroom and Airlock Model}

In the paper, we study the positive pressure pharmaceutical cleanroom composed by a cleanroom and an airlock, and design the pressure differences are 30 $\mathrm{Pa}$ and $15 \mathrm{~Pa}$, respectively. Properties and configuration of the system in this study are shown in Figure 1. The three kinds of blue colors represent the three different pressures of the cleanroom $p_{1}$, airlock $p_{2}$ and the surrounding $p_{0}$.

The system's model is obtained by mass balance in the following.

$$
\frac{\mathrm{d} m}{\mathrm{~d} t}=\sum \dot{m}_{\text {in }}-\sum \dot{m}_{\text {out }}
$$

$\sum \dot{m}_{\text {in }}$ and $\sum \dot{m}_{\text {out }}$ (unit $\mathrm{kg} / \mathrm{s}$ ), represent change rates of inputting and outputting air mass in cleanrooms, respectively. According the ideal-gas relation of Boyle-Gay Lussac equation, we get

$$
p(t)=\frac{m(t) R T}{V}
$$

where $R$ is the gas constant of air, $V$ is volume of the cleanroom, $T$ is temperature of the cleanroom we suppose the temperature is a constant because the change of the temperature is little during the process. Suppose that the flow of the cleanroom is turbulent, the airflows through the leakage areas can be calculated by the following equation

$$
\dot{m}=k \sqrt{P_{I}-P_{I I}}
$$

where $k$ is matching conductance between the rooms with pressure $p_{1}$ and $p_{2}$.

According Equations ((1), (3)), we get the formula of the mass change rate

$$
\frac{\mathrm{d} m}{\mathrm{~d} t}=\dot{m}_{\text {in_clean }}-k_{\text {sp12 }} \sqrt{p_{1}-p_{2}}-k_{d r} \sqrt{p_{1}-p_{2}}-k_{\text {sp10 }} \sqrt{p_{1}-p_{0}}-\dot{m}_{\text {out_clean }}
$$

where $\dot{m}_{\text {in_clean }}, \dot{m}_{\text {out_clean }}$ are supply and return airflow, respectively,

$k_{s p 10}, k_{s p 12}, k_{d r}$ are leakage conductances. Based on Equations (1) and (3), we obtain the airlock model

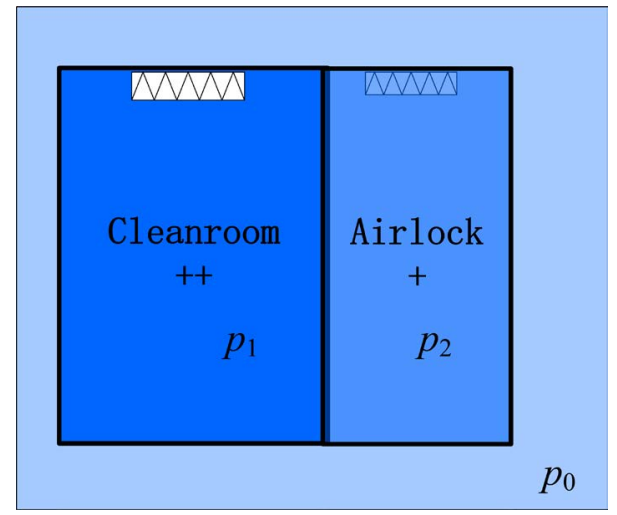

Figure 1. The diagram of positive pressure pharmaceutical cleanroom. 
Table 1. The system's parameters.

\begin{tabular}{cccccc}
\hline parameter & value (unit) & parameter & value (unit) & parameter & value (unit) \\
\hline$R$ & $287 \mathrm{~J} /(\mathrm{kg} \cdot \mathrm{K})$ & $\dot{m}_{\text {ir_air }}$ & $0.09904 \mathrm{~kg} / \mathrm{s}$ & $k_{\text {sp10 }}$ & $0.00792 \mathrm{~kg} / \mathrm{s}$ \\
$T$ & $293.15 \mathrm{~K}$ & $\dot{m}_{\text {out_air }}$ & $0.11291 \mathrm{~kg} / \mathrm{s}$ & $k_{\text {sp12 }}$ & $0.00792 \mathrm{~kg} / \mathrm{s}$ \\
$p_{0}$ & $10^{5} \mathrm{~Pa}$ & $\dot{m}_{\text {in_clean }}$ & $0.79238 \mathrm{~kg} / \mathrm{s}$ & $k_{\mathrm{dr}}$ & $0.00792 \mathrm{~kg} / \mathrm{s}$ \\
$m_{\text {clean }}$ & $142.67 \mathrm{~kg}$ & $\dot{m}_{\text {out_clean }}$ & $0.76861 \mathrm{~kg} / \mathrm{s}$ & $k_{\text {sp20 }}$ & $0.00099 \mathrm{~kg} / \mathrm{s}$ \\
$m_{\text {air }}$ & $17.83 \mathrm{~kg}$ & $V_{\text {clean }}$ & $120 \mathrm{~m}^{3}$ & $V_{\text {air }}$ & $15 \mathrm{~m}^{3}$ \\
\hline
\end{tabular}

$$
\frac{\mathrm{d} m}{\mathrm{~d} t}=\dot{m}_{\text {in_air }}+k_{\text {sp12 }} \sqrt{p_{1}-p_{2}}+k_{d r} \sqrt{p_{1}-p_{2}}-k_{\text {sp20 }} \sqrt{p_{2}-p_{0}}-\dot{m}_{\text {out_air }}
$$

where $\dot{m}_{\text {in_air }}, \dot{m}_{\text {out_air }}$ are supply and return airflow, respectively. Combined Equations ((2) (3) (5)), we get the model of the system, and calculate the initial condition and list them in Table 1.

\section{Disturbances Classification of the Cleaner System}

In the process of producing for the pharmaceutical cleanrooms, there are many kinds of disturbances that make influence on the setting. Based on investigation, we classify the disturbances of the pharmaceutical cleanrooms into three types, the first disturbance is step which is caused pressure to increase and decrease suddenly by opening/closing the door, supply/return air valves broken, and exhaust hoods open suddenly; the second is ramp disturbance which is caused pressure change slowly by increasing of the resistance force of the pipes and tuning exhaust airflow slowly based on some reasons; the third is periodic disturbance which is caused by operating mode switch between occupied and unoccupied time and airflow periodic fluctuation.

\section{Simulations in DP Control of the Cleanroom}

\subsection{CAV Control}

CAV is a passive method to control cleanroom's DP, it keeps DP of the cleanroom around the design value by preserving the balance between supply and return airflow, the approach is operated by tuning manually airflow valves. We study the different disturbance makes influence on the pressure in CAV control.

1) Step disturbance

Experiment condition: the pressure of airlock increase rapidly $5 \mathrm{~Pa}$ at $t=70 \mathrm{~s}$, the pressure change of the cleanroom is shown in Figure 2(a).

Experiment condition: the pressure of airlock increase gradually $5 \mathrm{~Pa}$ from $t=$ $70 \mathrm{~s}$ to $80 \mathrm{~s}$, the change of cleanroom pressure is given in Figure 2(b).

2) Periodic disturbance (sine wave disturbance)

Experiment condition: sine wave disturbance of the airlock's pressure is added at $t=70 \mathrm{~s}$, amplitude is $5 \mathrm{~Pa}$, the change of cleanroom's pressure is shown in Figure 3. 


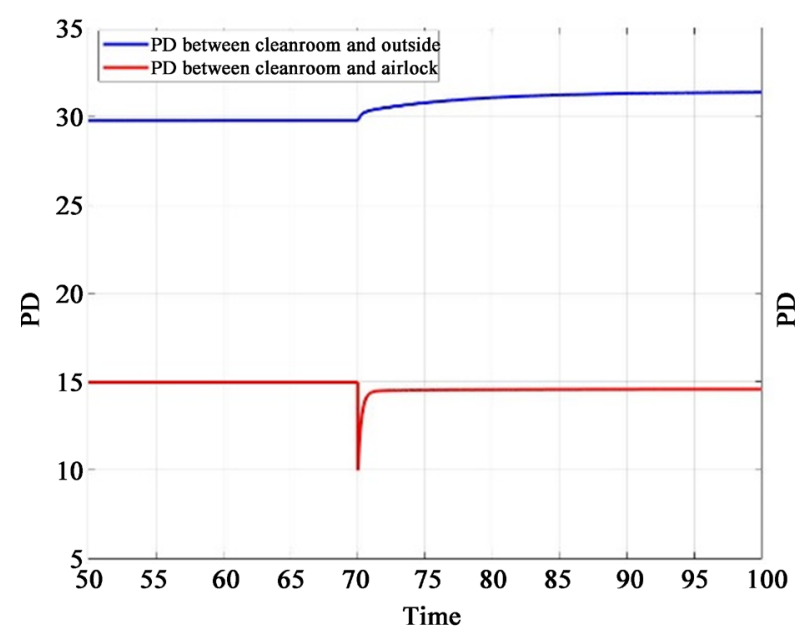

(a)

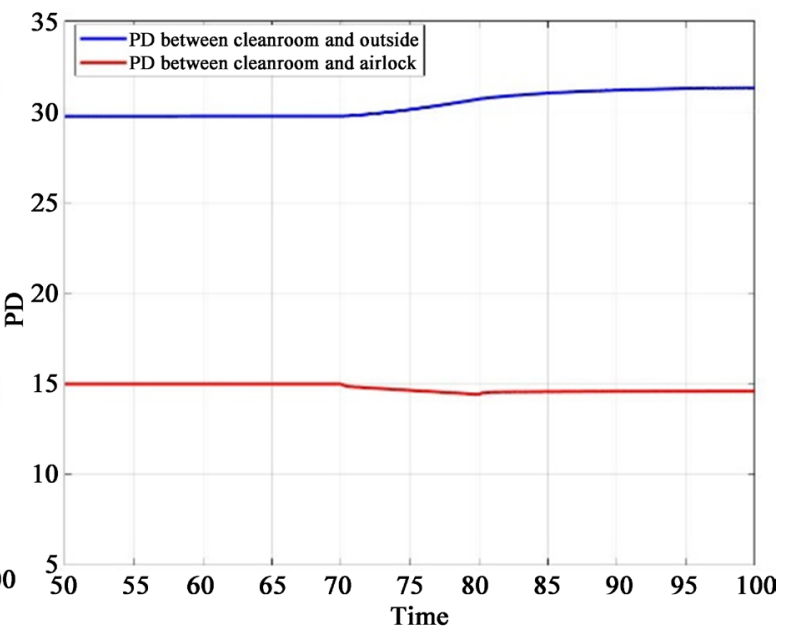

(b)

Figure 2. Change of cleanroom pressure in step and ramp disturbances. (a) Step disturbance; (b) Ramp disturbance.

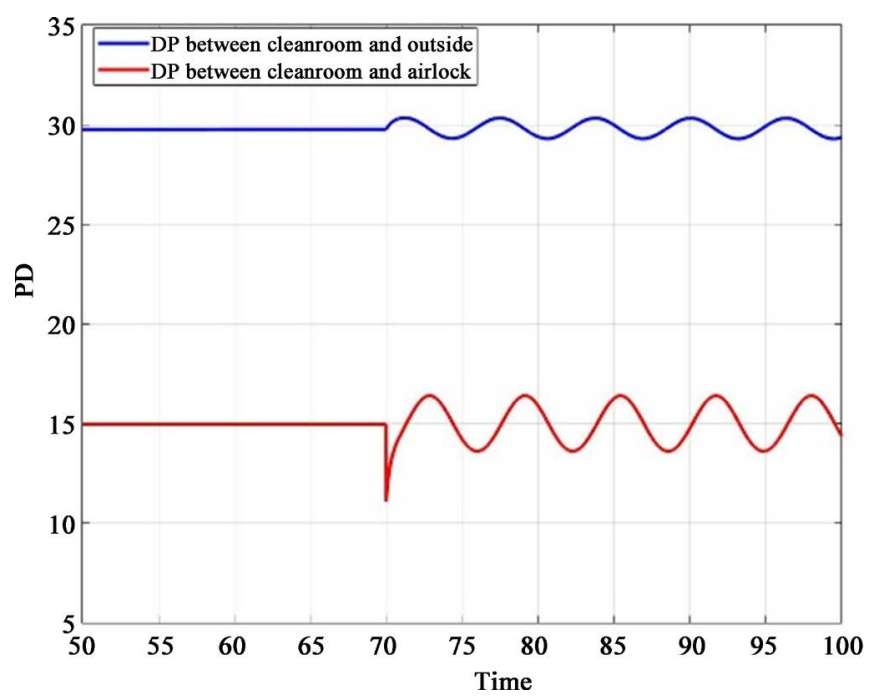

Figure 3. The change of the cleanroom's pressure difference in sine wave disturbance.

\subsection{VAV Control Method}

We control the cleanroom's pressure by the pressure difference sign which is collected by pressure sensor, and design PID control and active-disturbance-rejection-control. The control algorithm can maintain the required pressure gradient. The control diagram is dawn in Figure 4.

We build the equations of the pressure difference and airflows based on Figure 4:

$$
S A-R A=\Delta V=\Sigma Q=k_{10} \sqrt{P_{1}-P_{0}}+k_{12} \sqrt{P_{1}-P_{2}}+k_{d 12} \sqrt{P_{1}-P_{2}}
$$

Thus, the return airflow

$$
R A=S A-\left(k_{10} \sqrt{P_{1}-P_{0}}+k_{12} \sqrt{P_{1}-P_{2}}+k_{d 12} \sqrt{P_{1}-P_{2}}\right)
$$

\subsubsection{PID Control Diagram}

We build the simulating model in Matlab/Simulink software platform, and verified 
the rejection disturbance capability of the system, the experiment conditions are same with CAV control, the responding curves are given in Figure 5 and Figure 6.

The VAV control method on pressure difference has better abilities in rejecting disturbances than $\mathrm{CAV}$, it represents in lower responding time and higher control precision.

\subsubsection{Active-Disturbance-Rejection-Control on PD}

In this study, we choose linear active-disturbance-rejection-control (LADRC) to replace PID control in 4.2.1, the following formula is the expression of LESO.

$$
\left\{\begin{array}{l}
\dot{z}_{1}=z_{2}+\beta_{1}\left(-z_{1}+y\right)+b_{0} u \\
\dot{z}_{2}=\beta_{2}\left(-z_{1}+y\right)
\end{array}\right.
$$

where $u$ and $y$ are input and output of the controlled object, respectively, $\beta_{1}$ and $\beta_{2}$ are observer gains, the variables $z_{1}$ and $z_{2}$ of the LESO are approximated as $y$

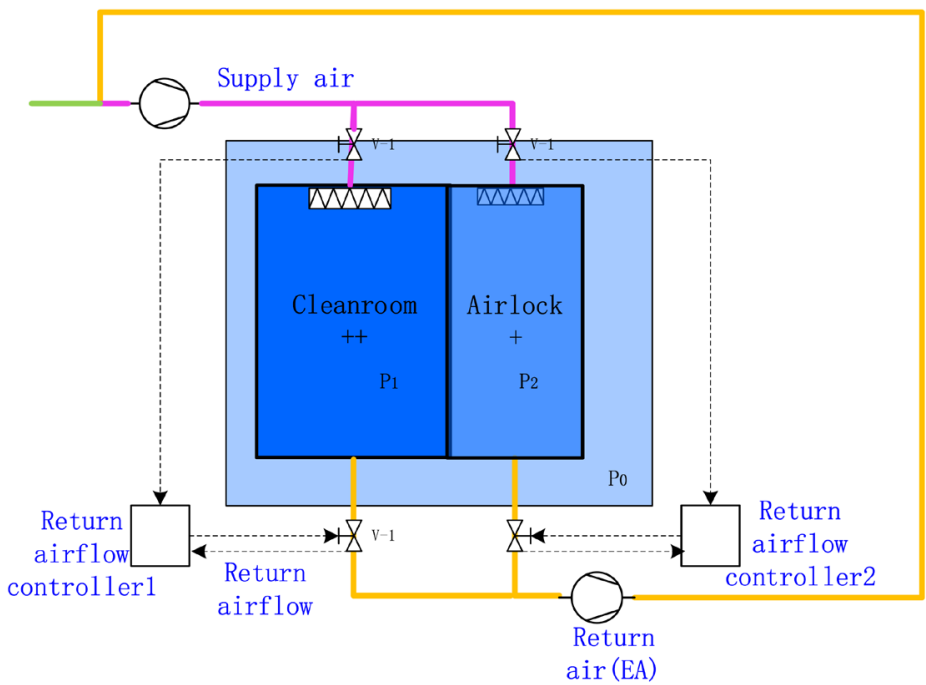

Figure 4. The control diagram of the VAV.
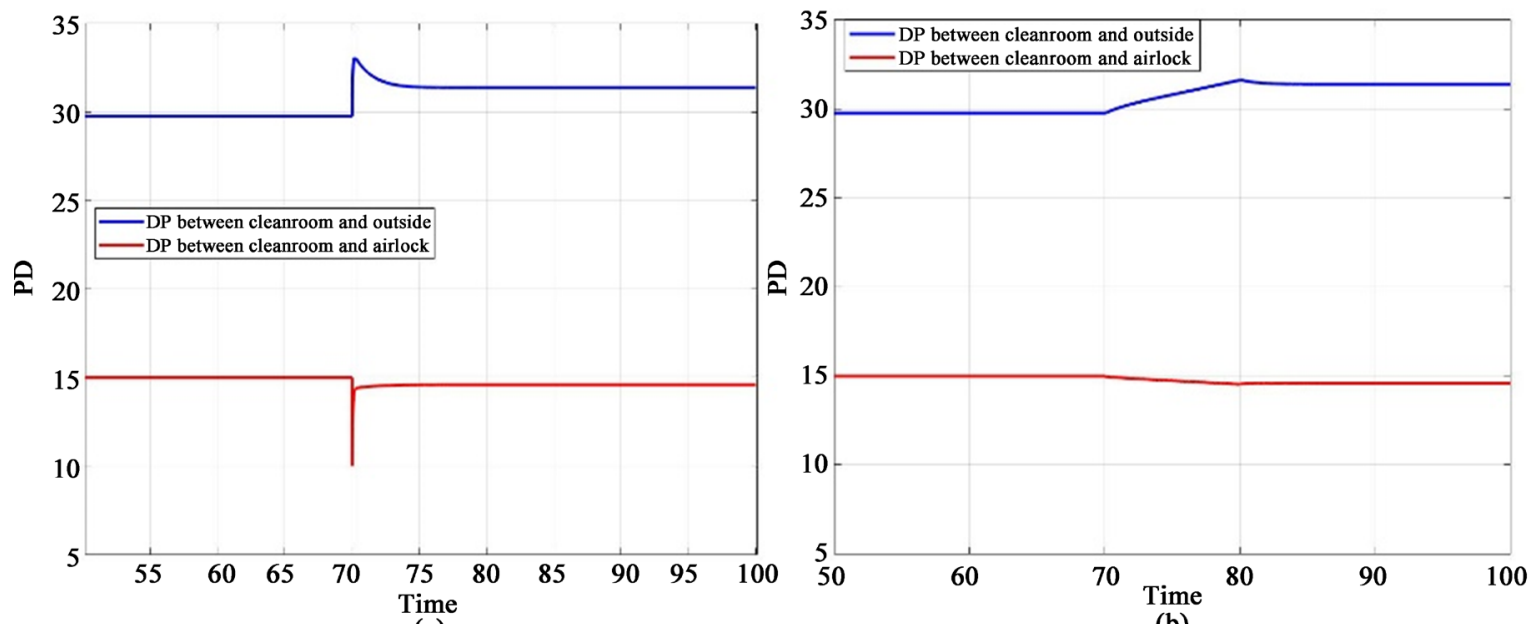

(a)

(b)

Figure 5. The responding curves of the system's pressure difference in PID control. (a) step disturbance; (b) ramp disturbance. 
and whole disturbances in real time, respectively. The control law of LADRC can be expressed as follows:

$$
\left\{\begin{array}{l}
u=\left(-z_{2}+u_{0}\right) / b_{0} \\
u_{0}=k_{p}\left(T_{r}-z_{1}\right)
\end{array}\right.
$$

The diagram of LADRC is given in Figure 7.

The responding curves are shown in Figure 8 \& Figure 9 when the system is

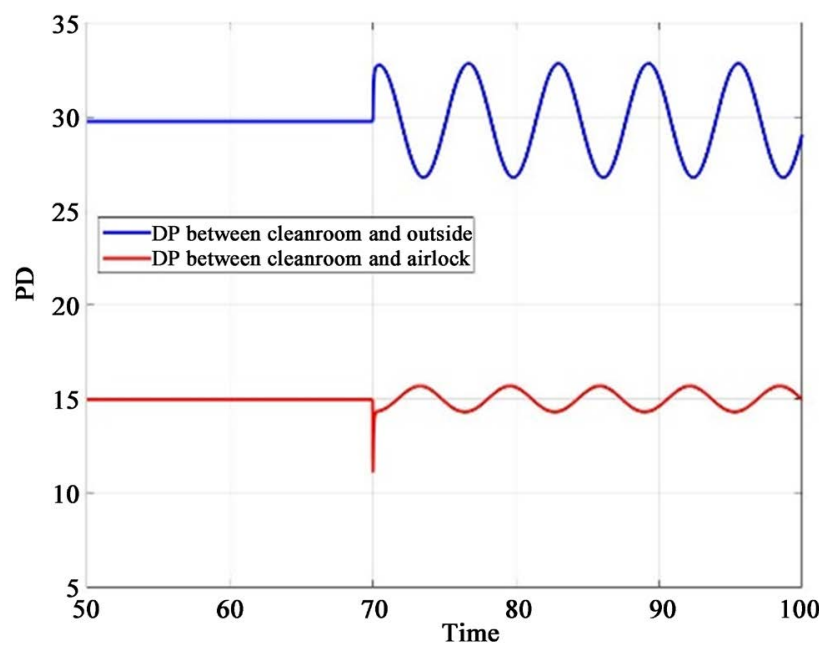

Figure 6. The responding curves of the system's pressure difference in sine wave disturbance.

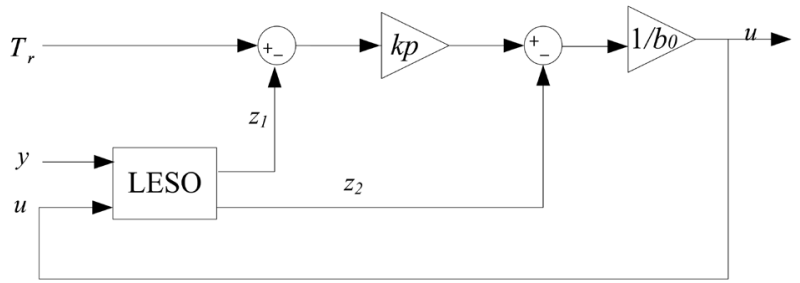

Figure 7. The diagram of LADRC.

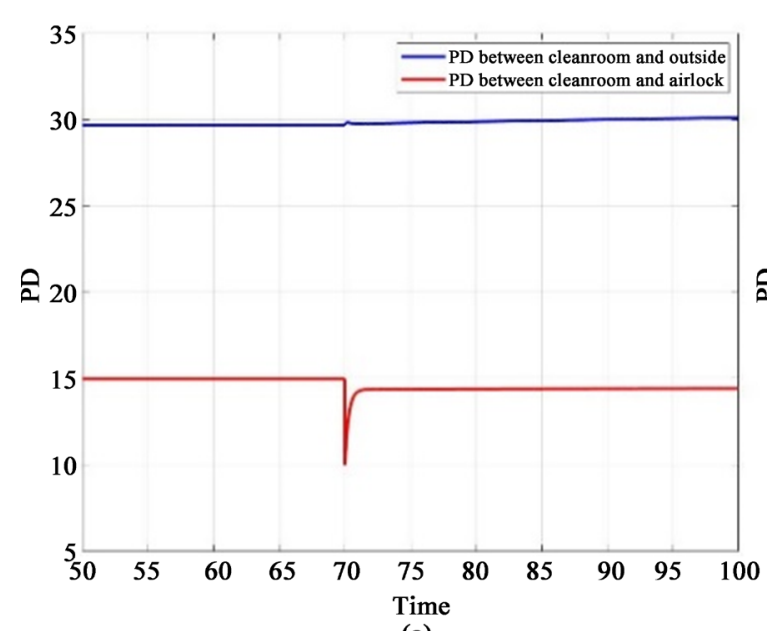

(a)

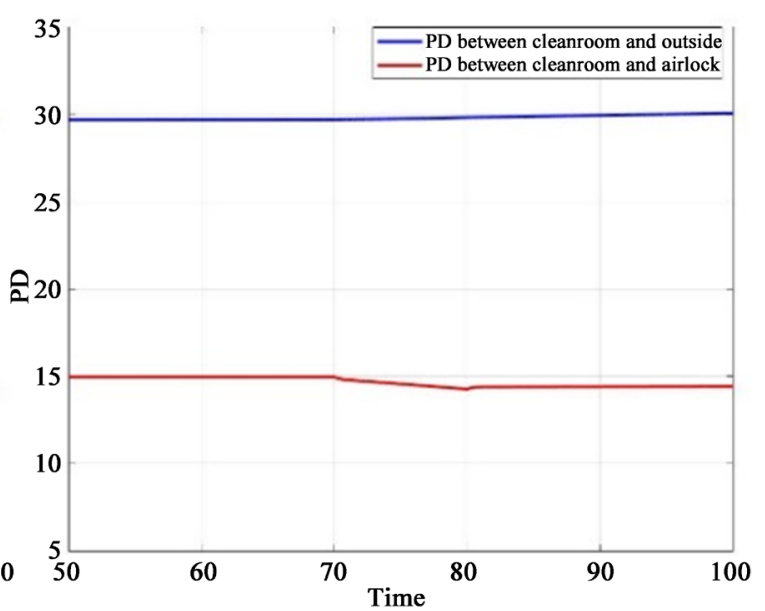

(b)

Figure 8. The responding curves of the system's pressure difference in LADC. (a) Step disturbance; (b) Ramp disturbance. 


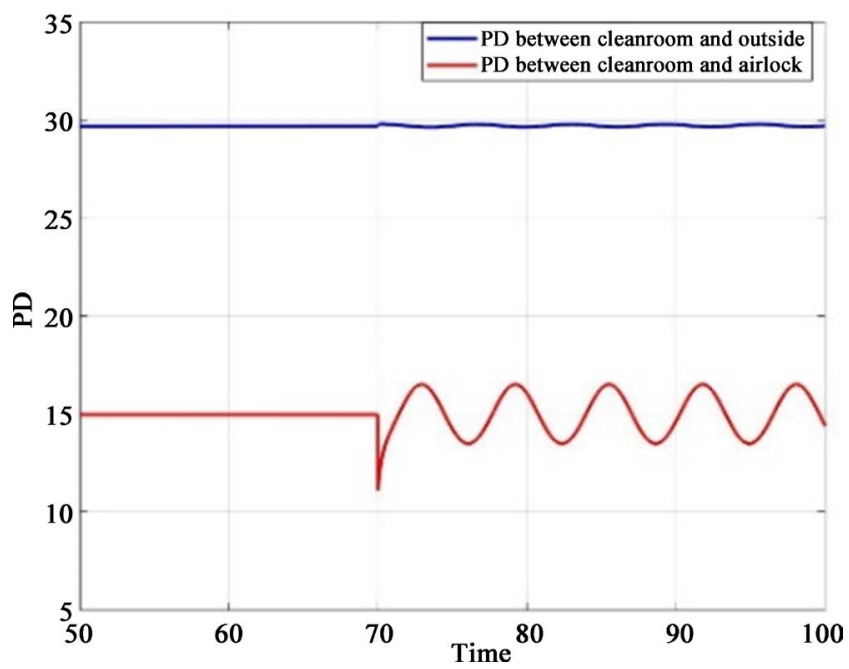

Figure 9. The responding curves of the system's pressure difference in sine wave disturbance.

Table 2. Contrastive analysis on simulation.

\begin{tabular}{lccccc}
\hline \multicolumn{2}{c}{ disturbance $(\mathrm{Pa})$} & index & CAV & PID control & LADRC \\
\hline \multirow{2}{*}{ step } & +5 & RT (s) & 15 & 5 & 3 \\
& & overshot (\%) & $4.67(2.80)$ & $4.63(2.80)$ & $0.33(3.87)$ \\
\multirow{2}{*}{ ramp } & $0-5$ & RT (s) & 15 & 12 & 11 \\
\multirow{2}{*}{ Sine wave } & amplitude 5 & amplitude (Pa) & $0.35(1.4)$ & $2.84(0.69)$ & $0.12(1.51)$ \\
\hline
\end{tabular}

influenced in disturbances.

Based on simulation of the three method of PD control, we compare quantitatively the results from responding time and overshot rate in Table 2.

\section{Conclusion}

There are many frequent disturbances in the manufacturing process of the pharmaceutical cleanroom. There is lower precision of the pressure control algorithm in factory. In this study, we propose to use a new control method to keep setting and avoid cross infection. The new approach is active-disturbance-rejectioncontrol which has strong disturbance rejection ability and high control precision. The VAV control algorithm based on LADRC is designed in typical cleanroom system which consists of an airlock and a cleanroom. The simulation results show that LADRC has better capability in responding time and overshot than traditional CAV control. Especially, LADRC has advantages in rejection disturbances and promoting control precision. The results propose an alternative approach for engineers in pressure control.

\section{Conflicts of Interest}

The authors declare no conflicts of interest regarding the publication of this paper. 


\section{Funding}

This project is supported the China National Key R\&D Program (Grant No. 2018 YFC0705201).

\section{References}

[1] Kircher, K., Shi, X., Patil, S. and Zhang, K.M. (2010) Cleanroom Energy Efficiency Strategies: Modeling and Simulation. Energy Build, 42, 282-289. https://doi.org/10.1016/j.enbuild.2009.09.004

[2] Xu, G.B. (1999) Cleanroom and Air Conditioning of Pharmaceutical Factory. China Architecture \& Building Press, Beijing. (In Chinese)

[3] Xu, Z.L. (2014) Air Cleanroom Technologies. The Fourth Edition, China Science Press, Beijing. (In Chinese)

[4] van den Brink, A.H.T.M. and van Schijndel, A.W.M. (2012) Improved Control of the Pressure in a Cleanroom Environment. Building Simulation, 5, 61-72.

https://doi.org/10.1007/s12273-012-0065-8

[5] Zamankhan, P. (2013) Risk Assessment in a Damaged Cleanroom by Using the Entropic Lattice Boltzmann Method. Journal of Aerosol Science, 66, 150-163. https://doi.org/10.1016/j.jaerosci.2013.08.015

[6] Wen, J., Sun, W. and Dost, S. (2009) Impact of Pressurization on Energy Consumption for Laboratories and Cleanrooms. ASHRAE Transactions, 115, 496-506.

[7] Liu, J.J., Zhao, X.Z. and Wang, B. (2007) Negative Pressure Difference Control in Biological Cleanrooms. Heating, Ventilation and Air Conditioning, 37, 85-57. (In Chinese)

[8] Shan, K. and Wang, S. (2017) Energy Efficient Design and Control of Cleanroom Environment Control Systems in Subtropical Regions-A Comparative Analysis and On-Site Validation. Applied Energy, 204, 582-595. https://doi.org/10.1016/j.apenergy.2017.07.050

[9] Wang, Y., Li, Y.J. and Zhou, L.C. (2015) Pressure Gradient Control and Energy-saving Operation Strategy Study on a Multi-Zone Cleanroom. Procedia Engineering, 121, 1998-2005. https://doi.org/10.1016/j.proeng.2015.09.198

[10] Han, J.Q. (1998) Active Disturbance Rejection Control and Its Application. Control and Decision, 13, 19-23.

[11] Gao, Z., Huang, Y. and Han, J. (2001) An Alternative Paradigm for Control System Design. Proceedings of IEEE Conference on Decision and Control, Orlando, 4-7 December 2001, 4578-4585.

[12] Han, J. (2009) From PID to Active Disturbance Rejection Control. IEEE Transactions on Industrial Electronics, 56, 900-906.

https://doi.org/10.1109/TIE.2008.2011621

[13] Gao, Z. (2003) Scaling and Bandwidth Parameterization Based Controller Tuning. Proceedings of the American Control Conference, Vol. 6, 4989-4996.

[14] Huang, C.E., Li, D.H. and Xue, Y.L. (2013) Active Disturbance Rejection Control for the ALSTOM Gasifier Benchmark Problem. Control Engineering Practice, 21, 556564. https://doi.org/10.1016/j.conengprac.2012.11.014

[15] Sun, L., Li, D., Hu, K., et al. (2016) On Tuning and Practical Implementation of Active Disturbance Rejection Controller: A Case Study from a Regenerative Heater in a 1000 MW Power Plant. Industrial \& Engineering Chemistry Research, 55, 66866695. https://doi.org/10.1021/acs.iecr.6b01249 
[16] Huang, C.E. and Liu, Z.L. (2015) Multi-Objective Optimization for Decentralized PI Control of the ALSTOM Benchmark Problem. Chinese Control Conference, Hangzhou, 28-30 July 2015. https://doi.org/10.1109/ChiCC.2015.7259725

[17] Huang, C.E. and Li, D.H. (2015) Multi-Objective Optimization for Active Disturbance Rejection Control for the ALSTOM Benchmark Problem. International Journal of Clean Coal and Energy, 4, 61-68.

[18] Huang, C.E., Li, C.W. and Ma, X.J. (2018) Active Disturbance Rejection Control for Temperature Control of the HVAC System. Intelligent Control and Automation, 9, 1-9. https://doi.org/10.4236/ica.2018.91001

[19] Xue, W.C., Huang, C.D. and Huang, Y. (2013) Design Methods for the Integrated Guidance and Control System. Control Theory \& Applications, 30, 1511-1520.

[20] Wei, W., Xue, W.C. and Li, D.H. (2018) On Disturbance Rejection in Magnetic Levitation. Control Engineering Practice, 82, 24-35. https://doi.org/10.1016/j.conengprac.2018.09.018

[21] Zheng, Q.L., Ping, Z., Soares, S., Hu, Y. and Gao, Z.Q. (2018) An Optimized Active Disturbance Rejection Approach to fan Control in Server. Control Engineering Practice, 79, 154-169. https://doi.org/10.1016/j.conengprac.2018.07.003

[22] Zheng, Q. and Gao, Z.Q. (2012) An Energy Saving, Factory-Validated Disturbance Decoupling Control Design for Extrusion Process. World Congress on Intelligent Control and Automation, Beijing, 6-8 July 2012, 2891-2896. https://doi.org/10.1109/WCICA.2012.6358364

[23] Line Stream Technologies Signs Licensing Deal with Texas Instruments. The Plain Dealer, July 12th, 2011.

[24] Achieve Improved Motion and Efficiency for Advanced Motor Control Designs in Minutes with TI's New Insta SPIN(TM)-MOTION Technology. The Wall Street Journal, April 18, 2013. 